\title{
Disability and satisfaction with access to health care
}

\author{
Bradley S Fouts, Elena Andersen, Kristofer Hagglund
}

\author{
Department of \\ Community Health, \\ Saint Louis University \\ School of Pubic \\ Health, St Louis, USA \\ B S Fouts \\ E Andersen \\ Missouri Model Spinal \\ Cord Injury System, \\ Department of \\ Physical Medicine and \\ Rehabilitation, \\ University of \\ Missouri-Columbia, \\ Columbia, USA \\ K Hagglund \\ Correspondence to: \\ Mr Fouts, 7172 S \\ Washington Street, Littleton, \\ CO 80122, USA \\ (bradfouts@att.net) \\ Accepted for publication \\ 26 May 2000
}

Table 1 Association of satisfaction with access to medical care with disability

\begin{tabular}{|c|c|c|c|c|c|c|}
\hline & \multicolumn{4}{|c|}{ Disability } & \multirow[b]{2}{*}{ POR } & \multirow[b]{2}{*}{$(95 \% C I)^{\star}$} \\
\hline & \multicolumn{2}{|c|}{ No $(n=2342)$} & \multicolumn{2}{|c|}{ Yes $(n=710)$} & & \\
\hline \multicolumn{7}{|l|}{ Satisfaction with access to medical care } \\
\hline Satisfied & 2155 & 92.0 & 615 & 86.6 & 1.00 & \\
\hline Not satisfied at all & 187 & 8.0 & 95 & 13.4 & 1.45 & $(1.07,1.96)$ \\
\hline \multicolumn{7}{|l|}{ Gender } \\
\hline Men & 1010 & 43.1 & 284 & 40.0 & 1.00 & \\
\hline Women & 1332 & 56.9 & 426 & 60.0 & 0.93 & $(0.76,1.12)$ \\
\hline \multicolumn{7}{|l|}{ Race } \\
\hline White & 2185 & 93.3 & 678 & 95.5 & 1.00 & \\
\hline Black & 74 & 3.2 & 14 & 2.0 & 2.35 & $(1.20,4.59)$ \\
\hline Asian, Pacific Islander & 45 & 1.9 & 2 & 0.3 & 6.12 & $(1.34,27.95)$ \\
\hline American Indian, Alaskan Native & 15 & 0.6 & 8 & 1.1 & 0.39 & $(0.15,1.01)$ \\
\hline Other & 25 & 1.1 & 8 & 1.1 & 0.89 & $(0.38,2.13)$ \\
\hline \multicolumn{7}{|l|}{ Marital status } \\
\hline Married/coupled & 980 & 58.2 & 352 & 49.6 & 1.00 & \\
\hline Not married & 2342 & 41.8 & 358 & 50.4 & 0.92 & $(0.75,1.14)$ \\
\hline \multicolumn{7}{|l|}{ Health status } \\
\hline Excellent & 672 & 28.7 & 64 & 9.0 & 1.00 & \\
\hline Very good & 973 & 41.5 & 191 & 26.9 & 0.51 & $(0.38,0.70)$ \\
\hline Good & 563 & 24.0 & 210 & 29.6 & 0.28 & $(0.21,0.38)$ \\
\hline Fair & 118 & 5.0 & 147 & 20.7 & 0.10 & $(0.07,0.14)$ \\
\hline Poor & 16 & 0.7 & 98 & 13.8 & 0.02 & $(0.01,0.04)$ \\
\hline \multicolumn{7}{|l|}{ Income } \\
\hline Less than $\$ 10000$ & 323 & 13.8 & 165 & 23.2 & 1.00 & \\
\hline$\$ 10000-\$ 15000$ & 255 & 10.9 & 107 & 15.1 & 1.11 & $(0.79,1.56)$ \\
\hline Greater than $\$ 15000$ & 1764 & 75.3 & 438 & 61.7 & 1.28 & $(0.97,1.68)$ \\
\hline Age & & & & & 0.98 & $(0.98,0.99)$ \\
\hline
\end{tabular}

${ }^{\star}$ Adjusted prevalence odds ratio (POR) and confidence intervals (CI) with all listed variables in the model.
Data that estimate international prevalence of disability are sparse. In the United States, estimates of the prevalence of persons with disability range from $3 \%$ to $20 \%$ of the population. ${ }^{1}$ Although some national level data are collected on disability, surveillance data are not collected routinely by most American state health departments. The purpose of this study was to examine the association between disability and access to health care using existing surveillance data. Ultimately, understanding these associations should assist public health officials to implement more effective, accessible, and acceptable public health intervention programmes to persons with disability.

\section{Methods}

Three special area random digit dialled telephone surveys were conducted in Missouri State from 1995 through 1997. Surveys and subject selection were based on the methods of the Behavioral Risk Factor Surveillance System (BRFSS), a health survey supported by the Centers for Disease Control and Prevention (CDC). Our outcome variable was disability status, based on a standard BRFSS question "are you limited in any way, in any activity, because of any impairment or health problem?" This question has been found to be reliable in disability samples, but groups together persons with disability who are fairly heterogeneous. ${ }^{34}$ Answers to the question: "How satisfied are you with your access to health care?" were categorised as positive or negative. We used logistic regression to compute the adjusted prevalence odds ratio (POR) to measure the association between disability and health care.

\section{Results}

A total of 3414 adults aged 18 and older completed the telephone surveys. They were $52.4 \%$ women, $95.8 \%$ white, with a mean age of 41.8 (standard deviation $(\mathrm{SD})=18.0)$. Altogether 710 respondents $(23 \%)$ reported they were limited and were classified as having a disability. The unadjusted POR was 1.78 (95\% confidence intervals $(95 \% \mathrm{CI})=1.37,2.31)$ indicating that those who were dissatisfied were more likely also to have a disability (table 1). The adjusted POR (by age, race, marital status, gender, income, health status) decreased modestly to $1.45(95 \% \mathrm{CI}=1.07,1.96)$. The Hosmer and Lemeshow goodness of fit test for this model was marginal $\left(\chi^{2} 14.1, \mathrm{df} 8, \mathrm{p}=0.08\right)$ and further examination of the residual cases (+ 2 standard deviations) showed a skewed distribution, with $91 \%$ of these cases in the negative tail.

\section{Conclusions}

The results show an association between satisfaction with access to health care and disability status. These results are consistent with previous research demonstrating that persons with disability report poorer access to needed services. ${ }^{5}$ However, both primary variables (disability and satisfaction with access) are likely to be have been measured with a fair amount of random misclassification, which would suggest our results have underestimated the association. This was a randomly selected surveillance sample, which strengthens our belief that these are not spurious associations. If persons with disability receive inadequate health care it may lead to health deterioration and the development of secondary conditions. Furthermore, poor access to effective, timely health care probably contributes to reduced community integration, ${ }^{5}$ diminished quality of life, and higher subsequent health care costs. Surveillance data suggest that people with disabilities have poorer access to heath care services, but more directed research questions would be needed to clarify this association. 
Other concerns about the results of this report include the one question variable measuring satisfaction with access to care that has not been validated against longer measures. However, the question has substantial face validity, and there was not a problem with missing data that would suggest subjects had problems understanding it. Furthermore, there is no "gold standard" survey measure of access to care. Psychometric data on longer measures are rarely published and not readily available.

This cross sectional survey does not provide data on the causal or temporal relation between satisfaction with access to health care and disability status. We cannot infer that poor access to health care causes disability or vice versa. Furthermore, this study sample was from selected counties in one Midwestern American state and may not be generalised to other communities. Nevertheless, these should be duplicated by other surveillance-based reports. However, given the limitations of cross sectional surveillance data, there also is a need to understand more about the details of access to care, satisfaction with care, and differences by disability status as well as other factors. For these studies, single surveillance questions will need to be replaced with longer instruments. For example, the American Agency for Healthcare Research and Quality (AHRQ, formerly AHCPR) and the Healthcare Financing Administration (HCFA) funded the development of the Consumer Assessment of Health Plans Study (CAHPS), resulting in a survey with much more detail about access and satisfaction with care..$^{7}$ In conclusion, we suggest that the health care needs of persons with disability may not be met by their health care systems. As health delivery continues to be refined in the USA and in other nations special attention may be needed for people with disabilities. Their diverse health care needs warrant the development of innovative models of care focusing on health promotion, prevention of secondary conditions, and community integration.

We especially wish to thank our colleagues from the Missouri Department of Health Disability Epidemiology and Health Project; Carol Brownson, Roger Crocker, Jeanette JacksonThompson, and Theophile Murayi.

Funding: this work was supported, in part, by a cooperative agreement from the Missouri Department of Health to the University of Missouri-Columbia, Washington University, and Saint Louis University.

Conflicts of interest: none.

1 Institute of Medicine. Disability in America: toward a national agenda for prevention. Washington, DC: National Academy Press, 1991

2 Remington PL, Smith MY, Williamson DF, et al. Design, characteristics, and usefulness of state-based behavioral risk factor surveillance: 1981-1987. Public Health Rep 1988;103:366-75.

3 Andresen EM, Fouts BS, Romeis JC, et al. Performance of health-related quality-of-life instruments in a spinal cord injured population. Arch Phys Med Rehabil 1999;80:87784.

4 Newschaffer CJ. Validation of the BRFSS HRQOL measures in a statewide sample. Atlanta: US Department of Health and Human Services, CDC, 1998.

5 Nelson L, Brown R, Gold M, et al. Access to care in Medicare HMOs. Health Aff 1997;16:148-56.

6 World Health Organization. ICIDH-2: International classification of functioning and disability. Beta-2 draft for field trials. cation of functioning and disability. Beta-2 draft

7 Hays RD, Shaul JA, Williams VS, et al. Psychometric properties of the CAHPS 1.0 survey measures. Consumer Assessment of Health Plans Study. Med Care 1999;37 (suppl 3): MS22-31

8 Schnaier JA, Sweeny SF, Williams VS, et al. Special issues addressed in the CAHPS survey of Medicare managed care beneficiaries. Consumer Assessment of Health Plans Study. Med Care 1999;37 (suppl 3):MS69-78. 